\title{
Echinostoma ilocanum Infection in Two Residents of Savannakhet Province, Lao PDR
}

\author{
Jong-Yil Chai ${ }^{1,2}$, Woon-Mok Sohn ${ }^{3, *}$, Jaeeun Cho ${ }^{2}$, Keeseon S. Eom ${ }^{4}$, Tai-Soon Yong ${ }^{5}$, Duk-Young Min ${ }^{6}$, \\ Eui-Hyug Hoang ${ }^{2}$, Bounlay Phommasack ${ }^{7}$, Bounnaloth Insisiengmay ${ }^{7}$, Han-Jong Rim ${ }^{8}$
}

\begin{abstract}
${ }^{1}$ Department of Parasitology and Tropical Medicine, Seoul National University College of Medicine, Seoul 03080, Korea; ${ }^{2}$ Korea Association of Health Promotion, Seoul 07653, Korea; ${ }^{3}$ Department of Parasitology and Tropical Medicine, and Institute of Health Sciences, Gyeongsang National University College of Medicine, Jinju 52727, Korea; ${ }^{4}$ Department of Parasitology and Medical Research Institute, Parasite Resource Bank, Chungbuk National University School of Medicine, Cheongju 28644, Korea; ${ }^{5}$ Department of Environmental Medical Biology, Institute of Tropical Medicine and Arthropods of Medical Importance Resource Bank, Yonsei University College of Medicine, Seoul 03722, Korea; ${ }^{6}$ Department of Microbiology and Immunology, Eulji University School of Medicine, Daejeon 34824, Korea; 'Department of Hygiene and Prevention, Ministry of Health, Vientiane, Lao PDR; ${ }^{8}$ Department of Parasitology, Korea University College of Medicine, Seoul 02841, Korea
\end{abstract}

\begin{abstract}
Adult specimens of Echinostoma ilocanum (Garrison, 1908) Odhner, 1911 (Trematoda: Echinostomatidae) were recovered from 2 riparian people who resided along the Mekong River in Savannakhet Province, Lao PDR. In fecal examinations done by the Kato-Katz technique, they revealed echinostome eggs together with eggs of Opisthorchis viverrini (and minute intestinal fluke eggs) and hookworms. To recover the adult flukes, they were treated with praziquantel 30-40 $\mathrm{mg} / \mathrm{kg}$ in a single dose and purged with magnesium salts. A total of 658 adult fluke specimens were recovered from the 2 people; 456 from case 1 and 202 from case 2. Specimens from case 1 consisted of 335 echinostomes (301 E. ilocanum and 34 species undetermined), 120 O. viverrini, and 1 Haplorchis taichui, and those from case 2 consisted of 36 E. ilocanum, 134 O. viverrini, and $32 \mathrm{H}$. taichui. Thus, the number of $E$. ilocanum specimens was 337 in total (average per person, 168.5). From this study, it is suggested that foodborne intestinal flukes and liver flukes are highly prevalent along the Mekong River in Savannakhet Province. The present report describes for the first time human infections with E. ilocanum in Lao PDR.
\end{abstract}

Key words: Echinostoma ilocanum, Opisthorchis viverrini, Haplorchis taichui, echinostome, echinostomiasis, Savannakhet, Lao PDR

Among the intestinal flukes infecting humans and animals, echinostomes (Echinostomatidae) are most harmful, and they can cause severe gastrointestinal symptoms, including epigastric or abdominal pain accompanied by diarrhea, easy fatigue, and malnutrition [1]. As reported in Artyfechinostomum malayanum and Artyfechinostomum oraoni infection, heavy worm loads may even lead to mortality of humans and pigs due to intestinal perforation or marked malnutrition and anemia [2,3]. A total of 21 echinostome species worldwide which belong to 8 genera (Echinostoma, Echinochasmus, Acanthoparyphium, Artyfechinostomum, Echinoparyphium, Himasthla, Hypoderaeum, and Isthmiophora) are currently known to infect humans [1].

In Lao People's Democratic Republic (Lao PDR), foodborne

\footnotetext{
- Received 12 January 2018, revised 30 January 2018, accepted 31 January 2018.

*Corresponding author (wmsohn@gnu.ac.kr)

(c) 2018, Korean Society for Parasitology and Tropical Medicine

This is an Open Access article distributed under the terms of the Creative Commons Attribution Non-Commercial License (http://creativecommons.org/licenses/by-nc/4.0) which permits unrestricted non-commercial use, distribution, and reproduction in any medium, provided the original work is properly cited.
}

trematodes, such as Opisthorchis viverrini, Haplorchis spp., and lecithodendriids are common together with soil-transmitted nematodes, including hookworms [4-9]. On the other hand, Schistosoma mekongi is endemic in southernmost areas of Lao PDR, particularly in the Khong Islands [10]. With regard to echinostomes, only 2 reports have been available. One is the report of Echinochasmus japonicus infection in 3 people in Savannakhet Province [11]. The other is the report of echinostome fluke infections (Echinostoma revolutum, A. malayanum, E. japonicus, and Euparyphium sp.) among residents of Khammouane Province [12]. However, human infections with Echinostoma ilocanum have never been documented. We report herein 2 cases of E. ilocanum infection along the Mekong River in Savannakhet Province, Lao PDR.

The Korea Association of Health Promotion, Seoul, Korea, and the Department of Hygiene and Prevention, Ministry of Health, Lao PDR conducted collaborative projects to control intestinal helminthiases in Lao PDR (2000-2011). During this period, we conducted stool surveys using the Kato-Katz tech- 


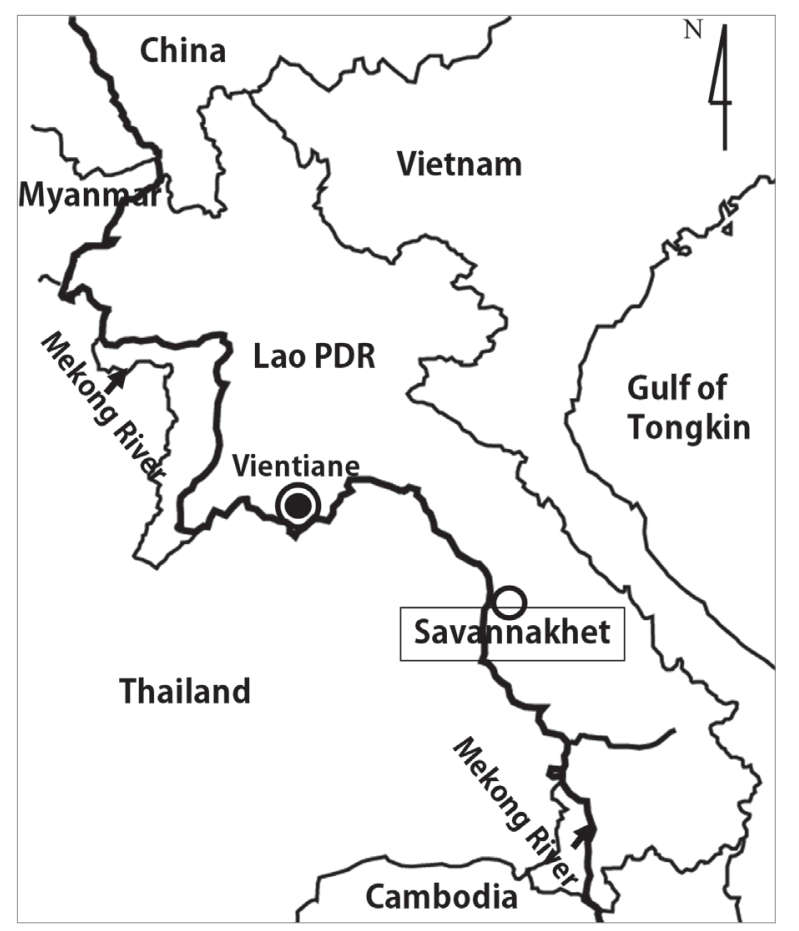

Fig. 1. A map showing the surveyed area (small circle, Savannakhet) in Lao PDR.

nique in various localities, including 4 riparian villages (Houay South, Houay North, Nang Soung, and Xok) of the Mekong River in Savannakhet Province (Fig. 1). We found several echinostome egg-positive cases mixed-infected with Opisthorchis viverrini (and minute intestinal fluke) in Houay North and Nang Soung villages. Adult flukes were recovered from 2 cases (case 1, 53-year-old male; case 2, 52-year-old female) who resided in Houay North village.

The procedure of worm collection was as described previously [5-9]. Briefly, the egg-positive cases were given a single oral dose of 30-40 mg/kg praziquantel (Shinpoong Pharm. Co., Seoul, Korea) and an hour later purged with 20-30 g $\mathrm{MgSO}_{4}$. Adult flukes were collected from the diarrheic stools and washed several times in water. They were fixed in 10\% formalin under a cover slip pressure, stained with acetocarmine, and morphologically examined. Fecal examination of the village residents and worm recovery from the 2 cases were officially approved by the Ministry of Health, Lao PDR, under the agreement of the Korea-Laos International Collaboration on Intestinal Parasite Control in Lao PDR (2000-2011). The worm recovery was performed after obtaining informed consent from each person.

From these 2 cases, a total of 658 adult fluke specimens
Table 1. Measurements of Echinostoma ilocanum adult specimens recovered from case 1 in Savannakhet Province, Lao PDR in comparison with those in a previous report

\begin{tabular}{lcc}
\hline \multirow{2}{*}{ Item } & \multicolumn{2}{c}{ Measurements in mm (mean) } \\
\cline { 2 - 3 } & $\begin{array}{c}\text { The present study } \\
(\mathrm{n}=10)\end{array}$ & $\begin{array}{c}\text { Lie and Nasemary [17] } \\
(\mathrm{n}=24)\end{array}$ \\
\hline Body length & $5.84-7.78(6.39)$ & $5.46-9.20$ \\
Body width & $0.99-1.34(1.22)$ & $0.62-1.56$ \\
Collar length & $0.18-0.23(0.20)$ & - \\
Collar width & $0.32-0.47(0.38)$ & $0.35-0.43$ \\
Oral sucker length & $0.14-0.21(0.17)$ & $0.18-0.24$ \\
Oral sucker width & $0.16-0.22(0.19)$ & $0.18-0.24$ \\
Ventral sucker length & $0.49-0.63(0.57)$ & $0.47-0.64$ \\
Ventral sucker width & $0.47-0.61(0.53)$ & $0.47-0.64$ \\
Ovary length & $0.11-0.27(0.20)$ & $0.18-0.44$ \\
Ovary width & $0.18-0.29(0.23)$ & $0.17-0.40$ \\
Anterior testes length & $0.54-0.69(0.61)$ & $0.47-1.18$ \\
Anterior testes width & $0.37-0.55(0.47)$ & $0.24-0.80$ \\
Posterior testes length & $0.53-0.79(0.66)$ & $0.52-1.21$ \\
\hline Posterior testes width & $0.31-0.53(0.44)$ & $0.23-0.70$ \\
\hline
\end{tabular}

were recovered; 456 from case 1, and 202 from case 2. The specimens from case 1 consisted of 301 E. ilocanum, 34 other echinostomes (species will be determined after molecular studies), 120 O. viverrini, and 1 Haplorchis taichui. Those from case 2 consisted of $36 \mathrm{E}$. ilocanum, $134 \mathrm{O}$. viverrini, and $32 \mathrm{H}$. taichui. The total number of E. ilocanum specimens was 337 (average no. per person, 168.5).

E. ilocanum adult flukes were elongated leaf-like (Fig. 2A-C), and averaged 6.39 (5.84-7.78) mm in length and 1.22 (0.99$1.34) \mathrm{mm}$ in width $(\mathrm{n}=10)$ (Table 1$)$. Both ends were attenuated, and the posterior end sometimes looked like slightly pointed. Around the oral sucker, the worms had 49-53 collar spines, most frequently 51 ( $>50 \%$ of the worms), arranged in 2 alternating rows, including 5 end group spines on each side (3 oral and 2 aboral) (Fig. 2D). The cirrus sac frequently passed beyond the half level of the ventral sucker, and the uterine tubule was somewhat long with a small to large number of eggs. The ovary was median or rarely submedian. The vitellaria extended laterally from the mid-level of the uterine tubule down to the posterior end of the body, and often the 2 groups of vitellaria merged near the posterior end of the body. Two testes were located post-equatorial; their shape was almost oblong without lobations in most of the specimens, but slightly or deeply lobed near the equatorial lines in rare instances. The eggs in the feces were large and oval, with a relatively narrow operculum and small abopercular wrinkles at the posterior end (Fig. 2D). The eggs in feces measured 101 

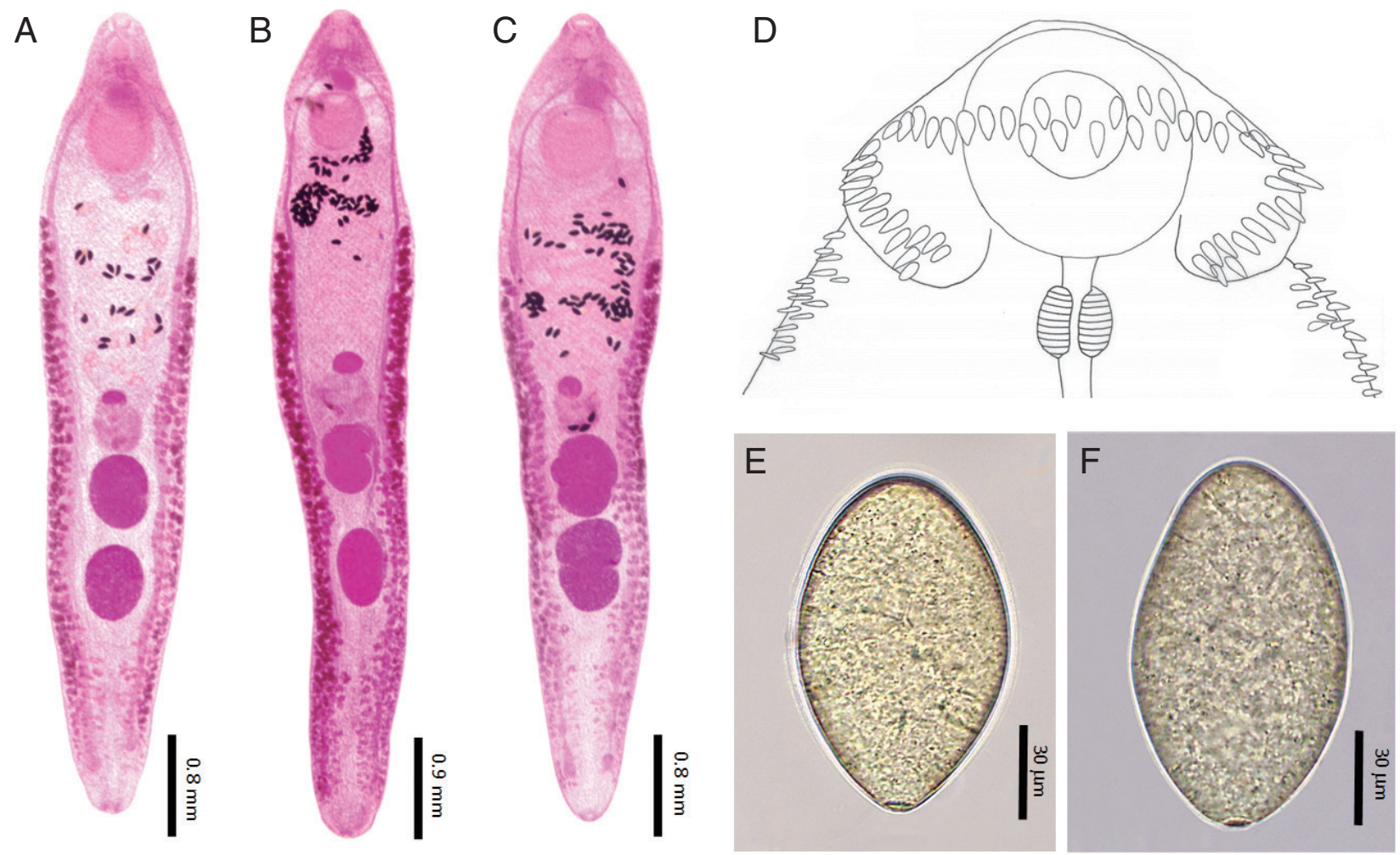

Fig. 2. Echinostoma ilocanum adults and eggs detected in our cases from Savannakhet Province, Lao PDR. (A) An adult specimen of E. ilocanum showing almost globular testes. (B) Another E. ilocanum specimen showing slightly lobed anterior testis and oblong posterior testis. (C) Another E. ilocanum specimen showing moderately (anterior testis) or deeply lobed testes (posterior testis). (D) Head collar showing a total of 51 collar spines, including 5 corner spines on each side, 3 oral and 2 aboral. Tegumental spines are quite large but smaller in comparison with collar spines. (E) An egg of $E$. ilocanum in the feces of case 2 . The operculum is small and inconspicuous at the anterior end, and abopercular wrinkles are also small and minute. (F) Another egg of $E$. ilocanum from case 2 showing similar findings.

(89-112) $\mu \mathrm{m}$ long and 61 (58-65) $\mu \mathrm{m}$ wide $(\mathrm{n}=15)$. All these morphological characters were compatible with previous descriptions of E. ilocanum [13-19].

Echinostome infections have been neglected because there is lack of information about this foodborne trematode group [12]. However, echinostome infections are not uncommon in some endemic localities, particularly in Southeast Asia and the Far East [1]. In addition, microscopists may overlook or misinterpret echinostome eggs as artefacts particularly in routine Kato-Katz fecal smears [12]. Moreover, eggs of different echinostome species closely resemble one another, and thus, for a specific diagnosis, adult worms should be recovered from each case and morphologically or molecularly identified [12].

In Lao PDR, with the exception of 2 reports, i.e., E. japonicus infection in 3 residents of Savannakhet Province [11] and $E$. revolutum, A. malayanum, E. japonicus, and Euparyphium sp. infections in 9 residents of Khammouane Province [12], no other echinostome infections have been documented in humans or animals. In the present study, we detected 2 E. ilocanum infected people in Savannakhet Province.

Echinostome infections can cause severe clinical manifestations, particularly in cases with heavy worm loads [1-3]. In our 2 cases, the worm load of E. ilocanum was fairly high, i.e., 301 and 36 worms per case, respectively. It should be referred that echinostome flukes, such as Isthmiophora hortensis (syn. Echinostoma hortense), can induce mucosal ulceration and bleeding in the duodenum and jejunum through mechanical irritation of the worms (using collar spines, and oral and ventral suckers) [1]. It is also of note that a 30-year-old Indian woman heavily (several hundreds of worms) infected with Artyfechinostomum malayanum (under the name A. mehrai) died due to marked malnutrition and anemia [2]. Both of our cases experienced severe gastrointestinal discomforts for several months duration. However, the clinical symptoms precisely due to $E$. ilocanum infection could not be figured out because they were co-infected with other parasites, including the liver fluke (O. 
viverrini) and intestinal fluke (H. taichui).

E. ilocanum was originally described from humans (prisoners) in Manila, the Philippines [13]. Eggs were detected in their feces, and from 1 patient 21 adult flukes were recovered after anthelmintic treatment [14]. This fluke was once transferred to the genus Euparyphium by Tubangui in 1931 [15]; however, this transference has not been readily admitted by other workers [16-18]. Thereafter, human infections have been reported from Indonesia (Celebes and Java), China, Thailand, the Philippines, India, and Cambodia $[1,16,17]$. By the present report, Lao PDR is newly included among the list of countries where E. ilocanum infection is distributed.

In the specific diagnosis of the present echinostome specimens, some difficulty was encountered because a few morphological differences were noted in our specimens compared to the descriptions made for E. ilocanum in previous reports. One of the most significant features was the shape of the 2 testes. Previous descriptions on the testes of E. ilocanum were variable. The testes were either round or slightly lobed [16], oblong with shallow or moderately deep indentations [17], deeply lobed [18], or rounded or slightly lobed but never deeply incised [19]. In our specimens, the testes were in most cases globular or oblong without lobations; only in rare instances, slightly or deeply lobed testes were observed. Therefore, in our opinion, the shape of the testes seems to be not a useful key for specific morphological diagnosis of E. ilocanum. Another significant morphological feature was the number of collar spines. Our specimens had 49-53 collar spines in most cases, and the most frequent number was 51. In an earlier report, the number of collar spines of E. ilocanum was 49 [13]. However, later it was reported by other workers as 49-51 [15,16,18], 49-55 [17], or even 50-60 [19]. Thus, it would be appropriate to set the number of collar spines in E. ilocanum as 49-55 (most frequently 49-51).

Human echinostome infections can be fish-borne, snailborne, or amphibian-borne [20]. E. ilocanum is a typical snailborne species, and large snails such as Pila conica, Viviparus javanicus, and Lymnaea rubiginosa brevis are known to be the major sources of infection $[1,20]$. However, in our cases, the source of infection is unclear. In Lao PDR, the life history of $E$. ilocanum is unknown, and the source of human infections should be investigated in the near future.

In conclusion, the results of the present study suggested that foodborne liver and intestinal flukes, including O. viverrini, E. ilocanum, and $H$. taichui, are prevalent along the Mekong River in Savannakhet Province, Lao PDR. This is the first report on human E. ilocanum infection in Lao PDR.

\section{ACKNOWLEDGMENTS}

We thank the staff of the Center for Laboratory and Epidemiology, Department of Hygiene and Prevention, Vientiane, and Provincial Health Department, Savannakhet, Lao PDR for their help in this work. We are also thankful to the staff of Korea Association of Health Promotion who participated in the Korea-Laos International Project on Intestinal Parasite Control in Lao PDR (2000-2011).

\section{CONFLICT OF INTEREST}

We declare that we have no conflict of interest related to this work.

\section{REFERENCES}

1. Chai JY. Echinostomes in humans. In: Fried B, Toledo R, eds, The Biology of Echinostomes. New York, USA. Springer. 2009, p 147-183.

2. Reddy DB, Ranganaykamma I, Venkataratnam D. Artyfechinostomum mehrai infestation in man. J Trop Med Hyg 1964; 67: 58-59.

3. Bandyopadhyay AK, Maji AK, Manna B, Bera DK, Addy M, Nandy A. Pathogenicity of Artyfechinostomum oraoni in naturally infected pigs. Trop Med Parasitol 1995; 46: 138-139.

4. Rim HJ, Chai JY, Min DY, Cho SY, Eom KS, Hong SJ, Sohn WM, Yong TS, Deodato G, Standgaard H, Phommasack B, Yun CH, Hoang EH. Prevalence of intestinal parasite infections on a national scale among primary schoolchildren in Laos. Parasitol Res 2003; 91: 267-272.

5. Chai JY, Park JH, Han ET, Guk SM, Shin EH, Lin A, Kim JL, Sohn WM, Yong TS, Eom KS, Min DY, Hwang EH, Phommasack B, Insisiengmay, Rim HJ. Mixed infections with Opisthorchis viverri$n i$ and intestinal flukes in residents of Vientiane Municipality and Saravane Province in Laos. J Helminthol 2005; 79: 1-8.

6. Chai JY, Han ET, Shin EH, Sohn WM, Yong TS, Eom KS, Min DY, Um JY, Park MS, Hoang EH, Phommasack B, Insisiengmay, Lee SH, Rim HJ. High prevalence of Haplorchis taichui, Prosthodendrium molenkampi, and other helminth infections among people in Khammouane Province, Lao PDR. Korean J Parasitol 2009; 47: 243-247.

7. Chai JY, Sohn WM, Yong TS, Eom KS, Min DY, Hoang EH, Phammasack B, Insisiengmay B, Rim HJ. Echinostome flukes recovered from humans in Khammouane Province, Lao PDR. Korean J Parasitol 2012; 50: 269-272.

8. Chai JY, Yong TS, Eom KS, Min DY, Jeon HK, Kim TY, Jung BK, 
Sisabath L, Insisiengmay B, Phommasack B, Rim HJ. Hyperendemicity of Haplorchis taichui infection among riparian people in Saravane and Champasak Province, Lao PDR. Korean J Parasitol 2013; 51: 305-311.

9. Chai JY, Sohn WM, Jung BK, Yong TS, Eom KS, Min DY, Insisiengmay B, Insisiengmay S, Phommasack B, Rim HJ. Intestinal helminths recovered from humans in Xieng Khouang Province, Lao PDR with a particular note on Haplorchis pumilio infection. Korean J Parasitol 2015; 53: 439-445.

10. Fukuhara K, Phompida S, Insisienmay S, Kirinoki M, Chigusa Y, Nakamura S, Matsuda H, Ishikawa H. Analysis of the effectiveness of control measures against Schistosoma mekongi using an intra- and inter-village model in Champasak Province, Lao PDR. Parasitol Int 2011; 60: 452-459.

11. Sayasone S, Tesana S, Utzinger J, Hatz C, Akkhavong K, Odermatt P. Rare human infection with the trematode Echinochasmus japonicus in Lao PDR. Parasitol Int 2009; 58: 106-109.

12. Chai JY, Sohn WM, Yong TS, Eom KS, Min DY, Hoang EH, Phammasack B, Insisiengmay B, Rim HJ. Echinostome flukes recovered from humans in Khammouane Province, Lao PDR. Korean J Parasitol 2012; 50: 269-272.

13. Odhner T. Echinostoma ilocanum (Garrison), eine neuer Menschenparasit aus Ostasien. Zool Anz 1911; 38: 65-68 (in Germany).
14. Cross JH, Basca-Sevilla V. Studies on Echinostoma ilocanum in the Philippines. Southeast Asian J Trop Med Public Health 1986; 17: 23-27.

15. Tubangui MA. Worm parasites of the brown rat (Mus norvegicus) in the Philippine Islands, with special reference to those forms that may be transmitted to human beings. Phil J Sci 1931; 46: 537-589.

16. Sohn WM, Kim HJ, Yong TS, Eom KS, Jeong HG, Kim JW, Kang AR, Kim MR, Park JM, Ji SH, Sinuon M, Socheat D, Chai JY. Echinostoma ilocanum infection in Oddar Meanchey Province, Cambodia. Korean J Parasitol 2011; 49: 187-190.

17. Lie KJ, Nasemary S. Studies on Echinostomatidae (Trematoda) in Malaya. XVI. The life history of Echinostoma ilocanum (Garrison, 1940). Proc Helminthol Soc Wash 1973; 40: 59-65.

18. Radomyos P, Bunnag D, Harinasuta T. Echinostoma ilocanum (Garrison, 1908) Odhner, 1911, infection in man in Thailand. Southeast Asian J Trop Med Public Health 1982; 13: 265-269.

19. Bonne C, Bras G, Lie KJ. Five echinostomes in man in the Malayan Archipelago. Am J Dig Dis 1953; 20: 12-16.

20. Yu SH, Mott KE. Epidemiology and morbidity of food-borne intestinal trematode infections. Trop Dis Bull 1994; 91: R125R152. 
